\title{
Исследование нелегированных нанокристаллических алмазных пленок, выращенных из газовой фазы в плазме СВЧ разряда
}

\author{
(С) А.Л. Вихарев ${ }^{1}$, С.А. Богданов ${ }^{1}$, Н.М. Овечкин ${ }^{1}$, О.А. Иванов ${ }^{1}$, Д.Б. Радищев ${ }^{1}$, А.М. Горбачев ${ }^{1}$, \\ М.А. Лобаев ${ }^{1}$, А.Я. Вуль ${ }^{2}$, А.Т. Дидейкин ${ }^{2}$, С.А. Краев ${ }^{1}$, С.А. Королев ${ }^{1}$ \\ ${ }^{1}$ Федеральный исследовательский центр Институт прикладной фризики Российской академии наук, \\ 603950 Нижний Новгород, Россия \\ ${ }^{2}$ Физико-технический институт им. А.Ф. Иоффе Российской академии наук, \\ 194021 Санкт-Петербург, Россия \\ E-mail: val@appl.sci-nnov.ru
}

Поступила в Редакцию 3 сентября 2020 г.

В окончательной редакции 10 сентября 2020 г.

Принята к публикации 10 сентября 2020 г.

Исследованы нелегированные нанокристаллические алмазные пленки толщиной менее одного мкм, выращенные на кремнии $\mathrm{Si}(100)$ методом плазмохимического осаждения из газовой фазы в плазме, поддерживаемой СВЧ излучением на частоте 2.45 ГГц. Для получения алмазных диэлектрических пленок с максимальным удельным сопротивлением было исследовано осаждение пленок в трех газовых смесях: водород-метановой смеси, в водород-метановой смеси с добавкой кислорода и в водород-метановой смеси с добавкой инертного газа. Установлена связь между условиями роста, структурными и электрическими свойствами нанокристаллических алмазных пленок. Показано, что для применения нанокристаллических алмазных пленок в качестве эффективных диэлектриков необходим предварительный высокотемпературный отжиг пленок, например, в вакууме при температуре $600^{\circ} \mathrm{C}$ в течение одного часа.

Ключевые слова: нанокристаллический алмаз, тонкие алмазные пленки, электрические свойства пленок.

DOI: 10.21883/FTP.2021.01.50387.9520

\section{1. Введение}

На протяжении уже более двадцати лет нанокристаллические алмазные (НКА) пленки вызывают неослабевающий интерес, вызванный наличием у них разнообразных весьма привлекательных свойств (см. обзоры [13]) и простотой их получения с помощью осаждения из газовой фазы. НКА пленки, как алмазный материал, близки по своим параметрам и свойствам таким, как модуль Юнга, твердость, оптическая прозрачность и теплопроводность, поликристаллическим алмазным пленкам. С другой стороны, они имеют свои, присущие только им характеристики, связанные с нанометровым размером составляющих НКА пленку кристаллитов и, следовательно, обилием межкристаллических границ и наличием модифицирующегося материала между кристаллитами (в зависимости от условий синтеза) НКА пленки, как правило, имеют толщину от 0.1 до 10 мкм, характерный размер кристаллитов от 5 до 200 нм и могут осаждаться на подложки из различных материалов. Эти пленки обладают высокой химической и радиационной стойкостью, отрицательным электронным сродством и способностью к полевой эмиссии, могут быть легированы в процессе роста различными примесями, поэтому представляют интерес для создания приборов микроэлектроники, микроэлектромеханических структур (МЭМС), защитных покрытий [4,5].

Отметим, что не существует универсальных НКА пленок, применимых сразу для всех приложений. Для каждого конкретного применения предъявляются соб- ственные требования к размеру кристаллитов, толщине, качеству, электропроводности и другим характеристикам НКА пленок, поэтому условия синтеза должны оптимизироваться для получения требуемых характеристик. Так, например, для синтеза НКА пленок с высокой электропроводностью используются водород-метановые газовые смеси со значительным содержанием инертного газа (аргона) [6] или азота или с одновременным добавлением этих примесей $[7,8]$. Увеличение содержания аргона или азота в смеси приводит к уменьшению размеров кристаллитов и увеличению доли неалмазной $\left(s p^{2}\right)$ фазы между кристаллитами, что улучшает эмиссионные свойства НКА пленок и делает такие пленки привлекательными для создания холодных катодов [9].

Цель данной работы - исследование нелегированных НКА пленок, выращенных на кремнии $\mathrm{Si}(100)$ методом плазмохимического осаждения из газовой фазы в плазме, поддерживаемой СВЧ излучением на частоте 2.45 ГГц. Основной задачей являлось получение однородных и в то же время тонких диэлектрических НКА пленок толщиной $0.1-1$ мкм.

В реакторах с СВЧ плазмой применяется несколько режимов осаждения нелегированных НКА пленок. Это осаждение НКА пленок в различных газовых смесях: водород-метановой смеси [10], в водород-метановой смеси с добавлением кислорода [11], в водород-метановой смеси с добавлением инертного газа [12]. В ряде работ были получены нелегированные НКА пленки, обладающие хорошими изоляционными свойствами, высокой теплопроводностью и удельным сопротивлением, 
близким к удельному сопротивлению пленок диоксида кремния $\sim 10^{14} \mathrm{OM} \cdot$ см [13]. Такие нелегированные НКА пленки изучались в первую очередь с целью разработки электронных приборов по технологии кремний-наалмазе $[14,15]$.

Однако, несмотря на отдельные удачные эксперименты, анализ возможностей перечисленных режимов роста диэлектрических НКА пленок не проводился. В данной работе наряду с измерениями структурных параметров (размеров кристаллитов, содержания различных фаз углерода) тонких (менее одного мкм) НКА пленок, полученных на кремниевых подложках при варьировании составов газовых смесей и режимов осаждения (температуры подложки и удельного энерговклада в плазму), представлены результаты измерения удельного сопротивления. Такой подход позволил выявить корреляцию электрических характеристик НКА пленок с их структурными свойствами.

Для получения воспроизводимого роста НКА пленок выполнялись два условия: во-первых, создание высокой плотности и однородности центров роста алмаза на всей поверхности кремниевой подложки и, во-вторых, поддержание одинаковых условий плазмохимического осаждения по всей поверхности подложки.

Выращенные НКА пленки исследовались методами рамановской спектроскопии, атомно-силовой микроскопии (ACM), сканирующей электронной микроскопии (электронный микроскоп JEOL 6390 LA), интерферометрии белого света. Диагностика плазмы СВЧ разряда проводилась методом оптической эмиссионной спектроскопии с помощью спектрометра Horiba Jobin Yvon FHR-1000 с CCD камерой Synapse CCD-2048×512. Проводимость НКА пленок определялась с помощью измерителя BAX (KEYSIGT B2901А) в диапазоне -200 до +200 В.

\section{2. Эксперимент}

\section{1. Установки для осаждения НКА пленок}

НКА пленки осаждались из газовой фазы на кремниевых подложках на двух установках, в которых с помощью плазмы, поддерживаемой СВЧ излучением на частоте 2.45 ГГц, создавались различные условия синтеза НКА пленок.

В первой установке плазмохимический реактор был создан на основе цилиндрического резонатора с диаметром, позволяющим с помощью коаксиальной линии возбуждать в нем сразу три аксиально-симметричные моды $\mathrm{TM}_{01 \mathrm{n}}, \mathrm{TM}_{02 \mathrm{n}}$ и $\mathrm{TM}_{03 \mathrm{n}}[16]$. На нижней торцевой стенке резонатора располагалась кварцевая колба, ограничивающая объем газа. У нижней стенки вне кварцевой колбы и вблизи боковой стенки резонатора располагался выступ переменной высоты с внутренним диаметром, выбранным так, чтобы мода $\mathrm{TM}_{03 n}$ затухала в нижней части резонатора. В результате сложения трех мод: $\mathrm{TM}_{01 \mathrm{n}}, \mathrm{TM}_{02 \mathrm{n}}$ и затухающей $\mathrm{TM}_{03 \mathrm{n}}$, над подложкой, установленной на подложкодержателе, формируется распределение ближнего электрического поля, регулируемое с помощью выступа. СВЧ излучение, генерируемое магнетроном в непрерывном режиме, подается в резонатор по волноводному тракту, соединенному с коаксиальной линией с антенной, которая возбуждает резонатор. В ограниченном объеме кварцевой колбы над подложкой поддерживается плазма СВЧ разряда. Реактор снабжен автоматическими системами подачи и откачки газа для поддержания требуемого давления газовой смеси. Держатель подложки соединен с системой водяного охлаждения для поддержания температуры подложки в требуемом диапазоне.

Вторая установка имела плазмохимический реактор, созданный на основе цилиндрического резонатора небольшого диаметра, в котором с помощью коаксиального волновода возбуждалась мода $\mathrm{TM}_{013}$ [17]. Резонансные условия в резонаторе достигаются путем перемещения его верхней подвижной стенки. Коаксиальный волновод соединен с прямоугольным волноводом и затем через циркулятор подключен к магнетрону. Область существования непрерывного разряда, так же как и в первом реакторе, ограничивается кварцевой колбой.

Установки позволяли получать НКА пленки при варьировании условий синтеза в широком диапазоне: давление газовых смесей 20-100 Торр, расход газов 100-500 кубических сантиметров в мин, СВЧ мощность $1-5$ кВт, температура подложки $600-900^{\circ} \mathrm{C}$, диаметр пластин монокристаллического кремния, имеющего ориентацию (100), составлял 20 мм.

\section{2. Подготовка кремниевых подложек для осаждения НКА пленок}

Обязательным условием для получения НКА пленок субмикронной толщины на неалмазной подложке является создание на ее поверхности центров роста алмаза. Плотность центров роста непосредственно определяет минимальную толщину сросшейся алмазной пленки. Наиболее распространенным методом подготовки неалмазных подложек является их обработка в суспензии наноалмазного порошка в ультразвуковой ванне. Под действием ультразвука алмазные частицы равномерно оседают на поверхность подложки и удерживаются на ней силами Ван-дер-Ваальса. Принципиальное влияние на характеристики засева в данном методе оказывает состав суспензии и размеры взвешенных в ней кристалликов алмаза. Появление и развитие промышленного метода детонационного синтеза алмаза со средним размером кристаллического зерна 4-5 нм [18] позволяет достичь концентрации центров кристаллизации $\sim 10^{11}-10^{12} \mathrm{~cm}^{-2}$.

Из литературы известно, что в первых экспериментах по росту нанокристаллических алмазных пленок применение детонационных наноалмазов (ДНА) позволяло 


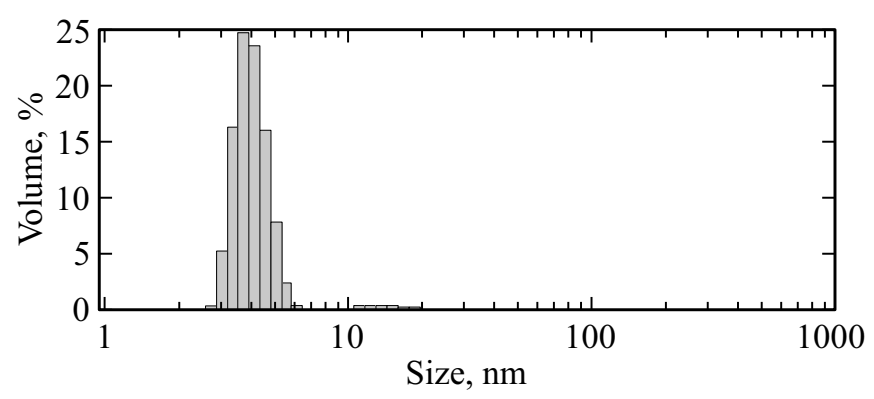

Рис. 1. Распределение размера наночастиц детонационного алмаза в использующейся суспензии.

осуществить рост пленок на подожках, материал которых не обладал химическим сродством к углероду [19], однако реализация концентрации центров $>10^{10} \mathrm{~cm}^{-2}$ столкнулась с так называемой проблемой агломерации. Частицы порошка ДНА представляли собой прочные агломераты кристаллических 4-5 нм зерен со средним размером $\sim 100$ нм [20]. Проблема деагломерации была решена в последние годы, что привело к получению стабильных гидрозолей частиц ДНА со средним размером частиц 4-5 нм [21].

В проведенных экспериментах применялась водная суспензия детонационного наноалмаза, полученная в ФТИ им. А.Ф. Иоффе. Массовая доля частиц составляла $0.4 \%$, их размер был $\sim 4-5$ нм (рис. 1$)$. В качестве исходного материала использовался промышленный ДНА производства СКТБ „Технолог“ (Санкт-Петербург, Россия). Промышленный порошок ДНА дополнительно очищался от металлических и инертных примесей, при этом содержание металлических примесей контролировалось методом ЭПР.

Деагломерация частиц ДНА проводилась по методу, описанному в работах [20,21]. Порошок ДНА подвергался отжигу на воздухе при температуре $\sim 450^{\circ} \mathrm{C}$ в течение нескольких часов. После этого выполнялось диспергирование навески отожженного ДНА в деминерализованной воде с использованием ультразвукового облучения. Полученный гидрозоль подвергался центрифугированию для осаждения остаточных агломератов. После центрифугирования гидрозоль ДНА содержал отдельные алмазные частицы размером 3-5 нм. Размеры и электрофоретическую подвижность частиц в гидрозолях ДНА измеряли методами динамического рассеяния света (ДРС) и лазерного доплеровского электрофореза соответственно. Измерения проводили на анализаторе Zetasizer Nano ZS (модель ZEN3600, Malvern Instruments, Англия).

Для создания центров роста (нуклеации) алмаза на поверхности подложки перед ростом проводилась предварительная подготовка подложек по методике, описанной в работах $[2,10]$. Все кремниевые подложки предварительно очищались в ацетоне в ультразвуковой ванне. Затем подложки подвергались ультразвуковой обработке в суспензии 5 нм порошка [20] в течение 30 мин. Условия ультразвуковой обработки были подобраны таким образом, что плотность центров роста алмаза достигала до $10^{12} \mathrm{~cm}^{-2}$, что в итоге в процессе CVD синтеза приводило к образованию сросшейся однородной пленки уже при толщинах $\sim 100$ нм. Исследования методом атомносиловой микроскопии (с радиусом иглы кантилевера 10 нм) показали, что после ультразвуковой обработки в суспензии 5 нм алмазных частиц на кремниевой подложке действительно наблюдаются отдельно расположенные алмазные наночастицы [21].

\section{3. Условия осаждения НКА пленок}

Для осаждения НКА пленок на кремниевых подложках использовалось три типа газовых смесей: водородметановая смесь при различном процентном содержании метана, водород-метановая смесь с добавкой кислорода и трехкомпонентная смесь водород-метан-инертный газ (гелий). Характеристики НКА пленок, выращенных в этих смесях, зависели как от состава смеси, так и от температуры подложки, которая независимо от величины СВЧ мощности и давления газа могла устанавливаться в диапазоне $600-900^{\circ} \mathrm{C}$ с помощью регулировки системы охлаждения подложки. Использование двух установок позволило выращивать НКА пленки при низких давлениях газовой смеси (30-50 Торр) в двух режимах: при низких (5-20 Вт/см ${ }^{3}$ на первой установке) и при относительно высоких $\left(60-90 \mathrm{BT} / \mathrm{cm}^{3}\right.$ на второй установке) удельных энерговкладах в плазму. Например, в одной из серий экспериментов режимы осаждения алмазных пленок, использованных на установках, отличались только значением удельного энерговклада (СВЧ мощности, поглощаемой в единице объема плазмы), в то время как другие параметры были сохранены. Условия осаждения и некоторые характеристики выращенных на гладких кремниевых подложках НКА пленок приведены в таблице, где $W$ - удельный энерговклад, $T_{S}$ - температура подложки, $P$ - СВЧ мощность, $p$ - давление газовой смеси, $d$ - толщина НКА пленки, FWHM - ширина „алмазной линии“ $\left(1332 \mathrm{~cm}^{-1}\right)$ на половине высоты в рамановском спектре комбинационного рассеяния.

В экспериментах температура кремниевой подложки измерялась с помощью инфракрасного пирометра M67/M67S компании MIKRON. Для измерения толщины НКА пленок в процессе их роста на кремнии использовалась зависимость интенсивности равновесного (теплового) инфракрасного (ИК) излучения пленки от ее толщины, приводящая к колебаниям измеряемой инфракрасным пирометром температуры пленки.

Осаждаемая на кремниевую подложку НКА пленка представляет собой по сути резонатор Фабри-Перо с длиной резонатора, соответствующей оптической толщине пленки. Изменение толщины пленки в процессе роста приводит к перестройке резонатора, что в свою очередь приводит к небольшим вариациям в спектре излучаемого равновесного теплового излучения. При определении температуры подложки с помощью ИК 
Условия осаждения и некоторые характеристики алмазных пленок

\begin{tabular}{|c|c|c|c|c|c|c|c|c|}
\hline Образец & $\begin{array}{l}\text { Состав газовой смеси } \\
\mathrm{H}_{2} / \mathrm{CH}_{4} / \mathrm{O}_{2} / \mathrm{He} \text {, sccm }\end{array}$ & $\begin{array}{c}W, \\
\text { Вт.с. }\end{array}$ & $\begin{array}{l}T_{S}, \\
{ }^{\circ} \mathrm{C}\end{array}$ & $\begin{array}{c}P, \\
\text { кВт }\end{array}$ & $\begin{array}{c}p, \\
\text { Topp }\end{array}$ & $\begin{array}{l}d, \\
\text { нм }\end{array}$ & $\begin{array}{c}F W H M \\
\mathrm{~cm}^{-1}\end{array}$ & $\begin{array}{c}\rho, \\
\Omega \cdot \mathrm{cm}\end{array}$ \\
\hline 1 & $\begin{array}{c}400 / 2 / 0 / 0 \\
\mathrm{CH}_{4} / \mathrm{H}_{2}=0.5 \%\end{array}$ & 9 & 710 & 4.0 & 38 & 700 & 6.5 & $4.3 \cdot 10^{9}$ \\
\hline 2 & $\begin{array}{c}200 / 2 / 0 / 0 \\
\mathrm{CH}_{4} / \mathrm{H}_{2}=1 \%\end{array}$ & 9 & 740 & 4.0 & 38 & 500 & 7 & $6.8 \cdot 10^{10}$ \\
\hline 3 & $\begin{array}{c}200 / 16 / 0 / 0 \\
\mathrm{CH} 4 / \mathrm{H} 2=8 \%\end{array}$ & & 710 & 2.25 & 35 & 560 & 10 & $1.3 \cdot 10^{7}$ \\
\hline 4 & $\begin{array}{c}\mathrm{CH} 4 / \mathrm{H} 2=2 \% \\
200 / 4 / 0 / 0\end{array}$ & 72 & 710 & 1.1 & 35 & 500 & 7 & $3.0 \cdot 10^{8}$ \\
\hline & $\begin{array}{c}5200 / 8 / 0 / 0 \\
\mathrm{CH}_{4} / \mathrm{H}_{2}=4 \%\end{array}$ & 72 & 710 & 1.1 & 35 & 500 & 7.7 & $1.1 \cdot 10^{6}$ \\
\hline 6 & $\begin{array}{c}200 / 16 / 0 / 0 \\
\mathrm{CH}_{4} / \mathrm{H}_{2}=8 \%\end{array}$ & 72 & 720 & 1.1 & 35 & 500 & 11 & $3.3 \cdot 10^{4}$ \\
\hline 7 & $\begin{array}{c}200 / 16 / 1 / 0 \\
\mathrm{O}_{2} / \mathrm{CH}_{4}=0.06\end{array}$ & 12 & 720 & 2.25 & 35 & 500 & 9 & $5.8 \cdot 10^{7}$ \\
\hline 8 & $\begin{array}{c}200 / 4 / 1 / 0 \\
\mathrm{O}_{2} / \mathrm{CH}_{4}=0.25\end{array}$ & 12 & 725 & 2.25 & 35 & 560 & 8 & $2.8 \cdot 10^{8}$ \\
\hline 9 & $\begin{array}{c}400 / 2 / 0.4 / 0 \\
\mathrm{O}_{2} / \mathrm{CH}_{4}=0.2\end{array}$ & & 725 & 2.25 & 35 & 400 & 8.5 & $5.1 \cdot 10^{7}$ \\
\hline 10 & $6 / 2 / 0 / 392$ & 10 & 670 & 1.75 & 220 & 500 & 10 & $1.8 \cdot 10^{10}$ \\
\hline 11 & $24 / 2 / 0 / 374$ & 12 & 740 & 2.1 & 220 & 700 & 7 & $6.7 \cdot 10^{10}$ \\
\hline 12 & $24 / 2 / 0 / 374$ & 9 & 680 & 1.6 & 220 & 700 & 6.5 & $4.5 \cdot 10^{11}$ \\
\hline
\end{tabular}

пирометра, регистрирующего излучение на одной длине волны, такое изменение спектра приводит к кажущемуся изменению измеряемой температуры (фактическая температура не изменяется, изменяются показания пирометра), что выглядит как небольшие вариации на графике изменения температуры от времени. По своей сути эти измерения толщины пленок аналогичны измерению толщины, предложенному в работе [22].

Для исследования характеристик НКА пленок в зависимости от режима осаждения нами выращивались пленки примерно одинаковой толщины, поскольку скорость осаждения пленок незначительно, но изменялась в различных газовых смесях. Осаждение пленок останавливалось после третьего максимума в показаниях температуры пирометра, что соответствовало толщине выращенной пленки 500-550 нм.

\section{3. Результаты экспериментов}

\section{1. Характеристики НКА пленок}

Далее описываются характеристики НКА пленок, выращенных в различных условиях, приведенных в таблице. Первая серия экспериментов была проведена с водород-метановой $\left(\mathrm{H}_{2} / \mathrm{CH}_{4}\right)$ газовой смесью при изменении содержания метана от 0.5 до 8\%. Известно, что при широком варьировании содержания метана в смеси можно получать НКА пленки как с различной микроструктурой (размером кристаллитов), так и с различным содержанием неалмазного углерода между кристаллитами [1-3]. На рис. 2 приведены (полученные с помощью сканирующего электронного микроскопа) изображения поверхности НКА пленок (образцы 1-3 в таблице), выращенных на первой установке (при низком удельном энерговкладе в плазму). Из рисунка видно, что микроструктура пленок изменяется с увеличением содержания метана в газовой смеси. При малом содержании метана $(0.5 \%)$ пленка имеет четко выраженную кристаллическую структуру с размерами кристаллитов до 300 нм в диаметре, в то время как при большом содержании метана (8\%) процессы ренуклеации приводят к появлению более мелких кристаллитов, увеличению доли неалмазной фазы в пленке, что отражается в спектрах рамановского рассеяния.

Для исследования характеристик выращенных НКА пленок методом спектроскопии комбинационного (рамановского) рассеяния использовалась установка на основе спектрометра Horiba Jobin Yvon FHR-1000 с матрицей ПЗС Symphony 2048×512BIVS, и непрерывного DPSS лазера мощностью до 1 Вт на длине волны 514 нм. Для фокусировки лазерного излучения на образец и сбора рассеянного излучения использовался модифицированный оптический микроскоп ЛОМО „Биолам-И“. Пространственное разрешение (размер пятна) в плоскости фокусировки составляло 1-2 мкм. На рис. 3 приведены рамановские спектры НКА пленок, выращенные при различных содержаниях метана в смеси: $0.5(a), 1(b)$ и $8 \%(c)$.

Как известно, в рамановских спектрах углеродных материалов наблюдается ряд типичных компонент. Спектр рамановского рассеяния алмаза имеет четкую линию 1-го порядка с волновым числом $\sim 1332 \mathrm{~cm}^{-1}$, растет 


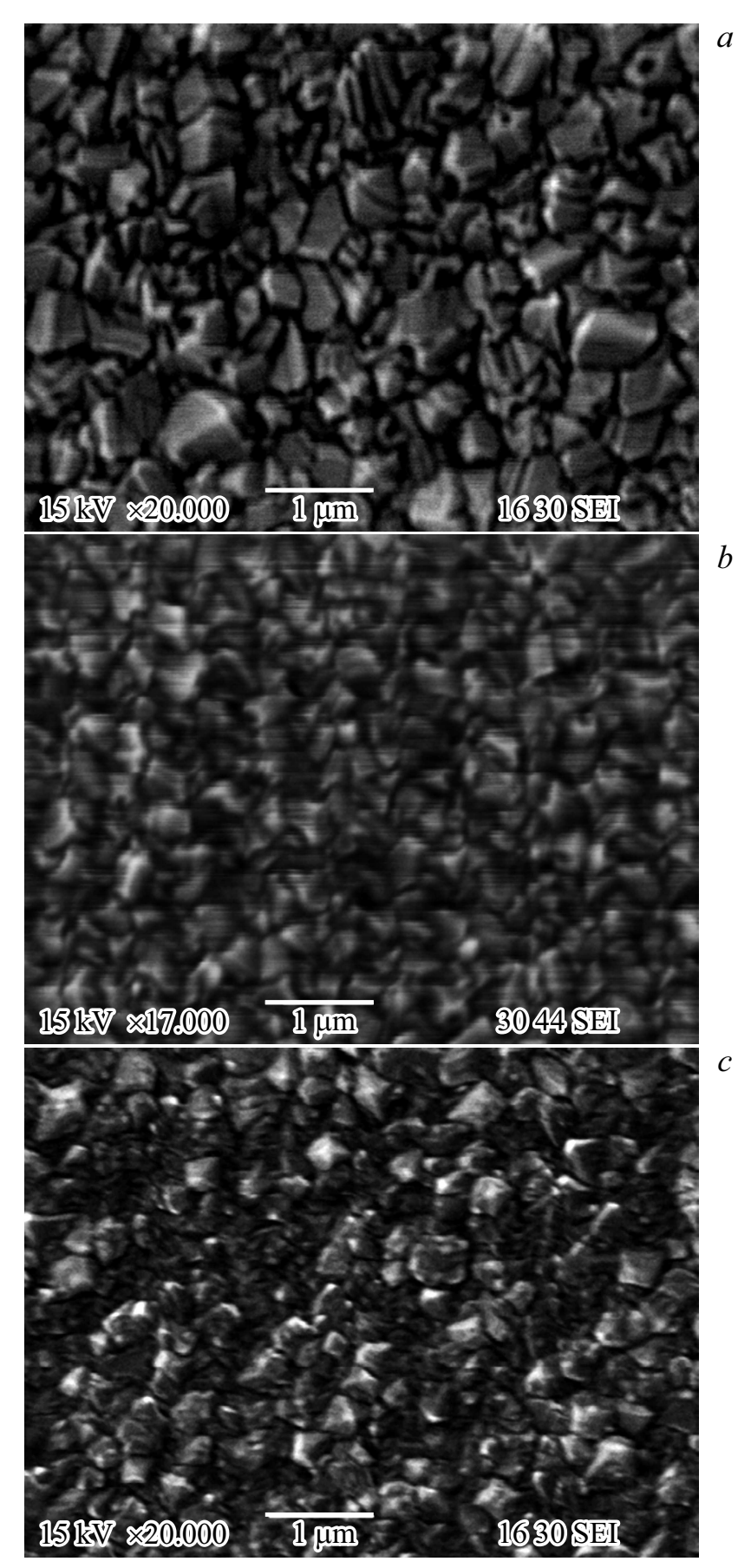

Рис. 2. Микроструктура поверхности НКА пленок толщиной 500 нм, выращенных при различных содержаниях метана $\mathrm{CH}_{4}$ : $0.5(a), 1(b), 8 \%(c)$.

$F W H M$ алмазной линии с ухудшением качества кристалла (увеличением плотности дефектов), а также с уменьшением размера кристаллитов. Спектр рамановского рассеяния идеального кристалла графита имеет один узкий пик на частоте $1580 \mathrm{~cm}^{-1}$. Так как включения графита в НКА пленке имеют нано-размеры и не могут рассматриваться как бесконечный кристалл, пик графита превращается в широкополосное излучение в диапазоне
$1560-1590 \mathrm{~cm}^{-1}$ ( $G$-пик), а также в спектре появляется излучение, связанное с неупорядоченным углеродом $\left(D\right.$-пик) в районе $1350 \mathrm{~cm}^{-1}$ (,холм“ непосредственно под алмазным пиком $\left.1332 \mathrm{~cm}^{-1}\right)$. Спектр аморфного углерода представляет собой широкий асимметричный
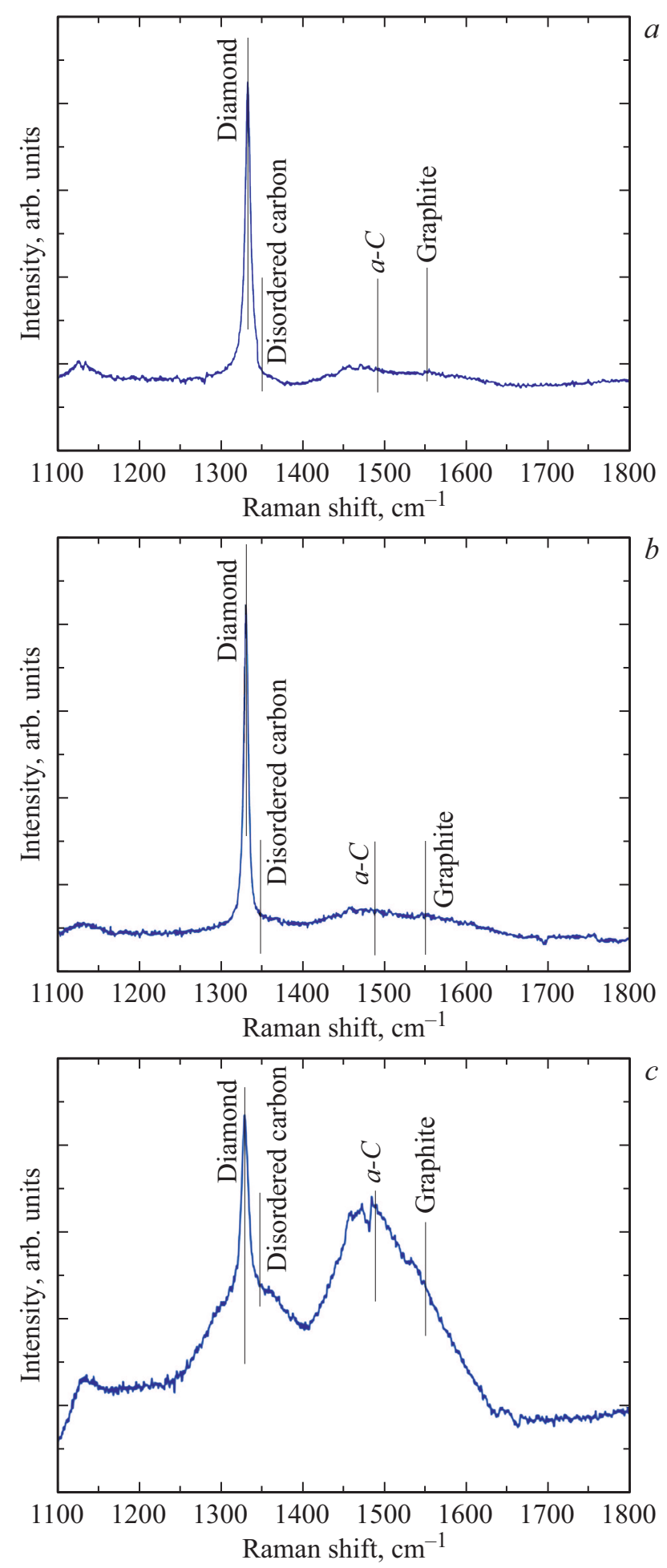

Рис. 3. Рамановские спектры НКА пленок толщиной 500 нм, выращенных при различных содержаниях метана $\mathrm{CH}_{4}: 0.5(a)$, $1(b), 8 \%(c)$. 


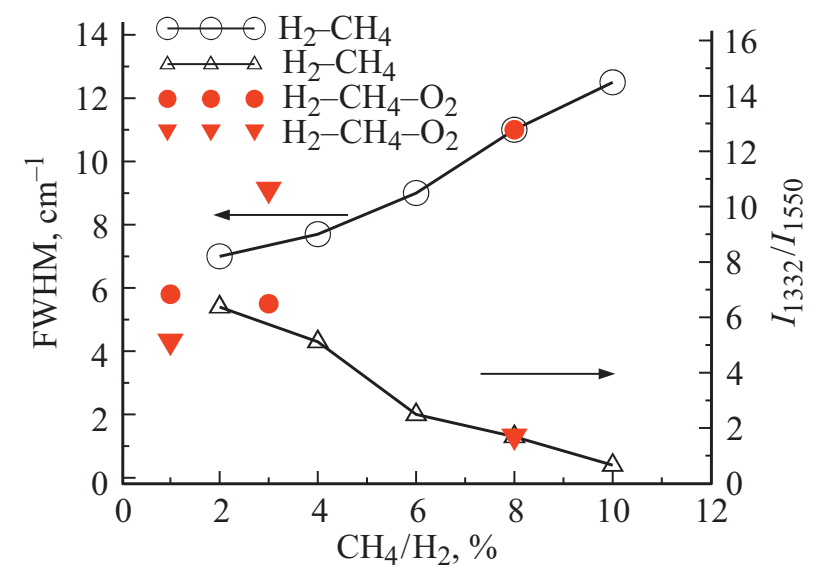

Рис. 4. Зависимость отношения интенсивностей линии алмаза $\left(1332 \mathrm{~cm}^{-1}\right)$ и $G$-линии $\left(1550 \mathrm{~cm}^{-1}\right)$ и $F W H M$ алмазного пика в рамановском спектре от содержания метана в смеси.

„холм“ в диапазоне $1000-1600 \mathrm{~cm}^{-1}$ с максимумом в районе 1450-1500 см${ }^{-1}$. На приведенных выше рисунках отмечено положение пиков излучения алмаза, неупорядоченного углерода, аморфного углерода $(a-C$-пик $)$ и графита $(G$-пик).

Из приведенных спектров хорошо видно, что по мере увеличения содержания метана в газовой смеси происходит уширение алмазной линии и существенное возрастание линий, соответствующих неалмазным формам углерода, сосредоточенных на границах кристаллитов.

Повторение экспериментов в $\mathrm{H}_{2} / \mathrm{CH}_{4}$ газовой смеси при более высоком удельным энерговкладе в плазму показало, что с ростом содержания метана происходило аналогичное изменение морфологии пленки и возрастание доли неалмазного углерода между кристаллитами (образцы 4-6 в таблице). Однако из-за большей концентрации атомов водорода, достигающейся в плазме при высоком энерговкладе, переход к ситуации, когда процесс вторичной нуклеации преобладает над процессом роста уже сформированных кристаллитов, происходил при более высоком содержании метана. Для выращенных НКА пленок в этом режиме, по данным рамановской спектроскопии, были определены зависимости отношения максимумов интенсивностей линии алмаза $\left(1332 \mathrm{~cm}^{-1}\right)$ и $G$-линии $\left(1550 \mathrm{~cm}^{-1}\right)$, а также $F W H M$ алмазного пика, от процентного содержания метана в смеси (рис. 4). Как видно из рисунка, $F W H M$ алмазного пика и доля графитовой $s p^{2}$-фазы в пленке, определяемая суммарным объемом границ кристаллитов, заметно возрастают при увеличении содержания метана.

Как видно из рис. 3 и 4, содержание неалмазного углерода между кристаллитами, влияющего на проводимость НКА пленок, становится заметным в пленках, выращенных уже при малом содержании метана $(<2 \%)$ в газовой смеси. Содержание неалмазного углерода на межкристаллитных границах в НКА пленке может быть уменьшено с помощью добавления кислорода в водород-метановую газовую смесь. Известно, что кислород уменьшает содержание $s p^{2}$-фазы и также ослабляет процессы ренуклеации, улучшает качество алмазных пленок и улучшает свойства границ кристаллитов [1]. Поэтому нами была проведена вторая серия экспериментов в газовой смеси $\mathrm{H}_{2} / \mathrm{CH}_{4} / \mathrm{O}_{2}$ при отношении $\mathrm{O}_{2} / \mathrm{CH}_{4}$, меняющемся в диапазоне от 0.06 до 0.25 (образцы 7-9 в таблице).

$F W H M$ алмазного пика и отношение максимумов интенсивностей линий 1332 и $1550 \mathrm{~cm}^{-1}$ для этих пленок представлены сплошными символами на рис. 4. Из рисунка видно, что при высоком (8\%) содержании метана в смеси, когда доля кислорода по отношению к $\mathrm{CH}_{4}$ невелика и составляет 0.06, добавка кислорода практически не влияет на характеристики НКА пленки. В то же время при низком содержании метана, с ростом отношения $\mathrm{O}_{2} / \mathrm{CH}_{4}$, доля неалмазной фазы падает, а полуширина алмазного пика уменьшается, следовательно, улучшается качество НКА пленки. Эффект улучшения качества НКА пленок с ростом доли кислорода в смеси наблюдался ранее в работе [11].

Отметим, что высокое качество НКА пленок может быть получено и в водород- метановой смеси, но при низком содержании метана. Так, в $\mathrm{H}_{2} / \mathrm{CH}_{4}$-смеси при содержании метана $0.3 \%$ были получены НКА пленки с содержанием неалмазной фазы $<0.1 \%$, которые были определены как пленки наивысшего качества [2]. Свойства таких пленок (теплопроводность, модуль Юнга, удельное сопротивление) близки к свойствам поликристаллических алмазных пленок. Как показали проведенные нами исследования, добавление кислорода в водород-метановую газовую смесь не приводит к существенному изменению морфологии НКА пленок, кристаллиты, по-прежнему, формируются в пленке в виде столбчатой структуры [4]. Однако в смеси с добавкой кислорода высокое качество пленки может быть получено при большем содержании метана в смеси, следовательно, при большей скорости роста.

В НКА пленках, получаемых в описанных выше режимах, скорость ренуклеации (прерывания роста кристаллитов) не очень высокая, в результате кристаллиты имеют вытянутую в направлении роста (столбчатую) структуру, т.е. тонкие пленки имеют близкую к 2D структуру [4]. Поэтому их изоляционные характеристики, в значительной мере определяемые свойствами границ кристаллитов, могут быть различными в направлении роста и вдоль поверхности подложки. Учитывая наличие неалмазной $s p^{2}$-фазы в межкристаллитическом объеме, процесс переноса заряда может осуществляться непосредственно вдоль неалмазных границ кристаллитов к поверхности кремниевой подложки.

Так как процесс вторичной нуклеации, приводящий к образованию новых центров роста алмазных кристаллитов на поверхности старых, всегда присутствует во время синтеза НКА пленок, то при определенных условиях он может стать преобладающим. Поэтому, варьируя режимы синтеза НКА пленок, можно подобрать условия, 

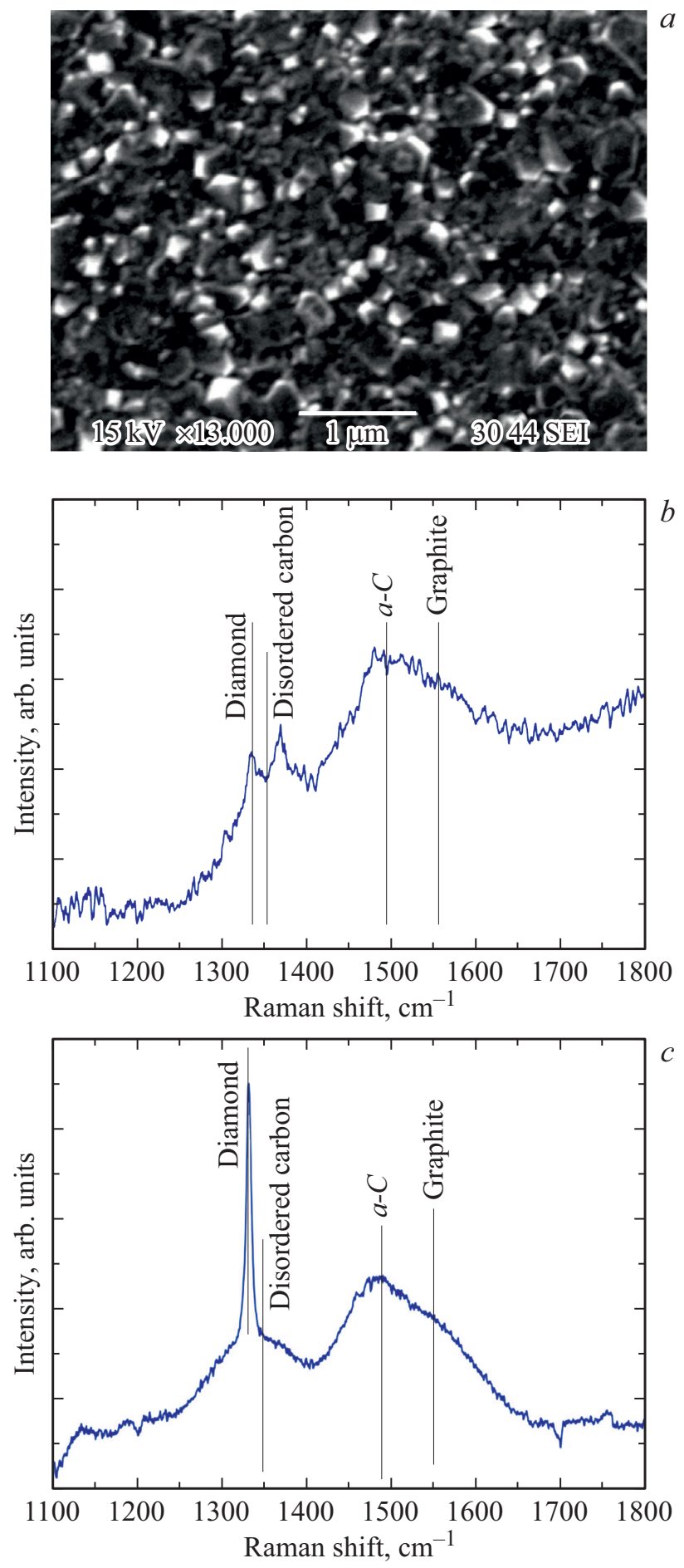

Рис. 5. Типичная микроструктура поверхности 3D НКА пленок толщиной $500 \mathrm{HM}(a)$ и рамановские спектры пленок, выращенных в смеси с добавкой инертного газа: $\mathrm{He}_{2} \mathrm{H}_{2}-\mathrm{CH}_{4}=392 / 6 / 2 \mathrm{sccm}, T_{S}=670^{\circ}(b)$ и $\mathrm{He} / \mathrm{H}_{2} / \mathrm{CH}_{4}=374 / 24 / 2 \mathrm{sccm}, T_{S}=740^{\circ}$ (c).

при которых процесс вторичной нуклеации имеет высокую скорость, кристаллиты имеют небольшие размеры и пленка приобретает 3D структуру с границами кристаллитов, ориентированными как вдоль, так и поперек поверхности подложки [4]. Для такой пленки ее свойства в направлении роста и вдоль поверхности подложки становятся одинаковыми, а процесс непосредственного переноса заряда от поверхности пленки к подложке будет затруднен.

В эксперименте НКА пленки с 3D структурой выращивались в третьей серии экспериментов в водородметановой смеси с добавкой инертного газа - гелия. Эксперименты выполнялись при общем потоке газовой смеси Не- $\mathrm{H}_{2}-\mathrm{CH}_{4}$, равном $400 \mathrm{sccm}$ (образцы 10-12 в таблице). На рис. 5 приведены типичная микрофотография и рамановские спектры 3D НКА пленок, выращенных при различном соотношении $\mathrm{CH}_{4} / \mathrm{H}_{2}$ в газовой смеси и двух температурах кремниевой подложки. Как видно из рис. 5, $b, c$, в выращенных пленках на межкристаллитных границах уже преобладает аморфный углерод $(a-C)$ по сравнению с графитом. Как известно, пленки из аморфного углерода обладают низкой проводимостью [23]. В нашем случае НКА пленки с повышенным содержанием $a-C$ фазы углерода (выращенные в смеси с добавкой гелия) так же обладали более высоким удельным сопротивлением.

\section{2. Измерения удельного сопротивления НКА пленок}

Для всех выращенных в трех сериях экспериментов НКА пленок исследовалось их удельное сопротивление, величина которого характеризует изоляционные свойства пленок. Проводимость НКА пленок определялась двухзондовым методом на основе анализа вольтамперных характеристик, получаемых с помощью измерителя BAX (KEYSIGT B2901А) в диапазоне -200 до +200 В. Измерения проводились по схеме контакт на поверхности пленки-НКА пленка-проводящая $\mathrm{Si}(n$-тип) подложка с индиевым контактом, а также по схеме между двумя точками на поверхности НКА пленки. Для формирования контактов на поверхности пленок методами фотолитографии изготавливались алюминиевые квадраты размером $1.3 \times 1.3 \mathrm{Mм}$.

Все вольт-амперные характеристики, как правило, имели квазисимметричную форму с линейной (омической) частью при низких напряжениях и резким нелинейным подъемом, начиная с некоторого порогового значения напряжения $V_{b}$. Значения $V_{b}$ для различных типов пленок обычно находились в диапазоне от 10 до 100 В. Типичный вид вольт-амперной характеристики для пленки, выращенной в водород-метановой газовой смеси, приведен на рис. 6, $a$. Отметим, что симметричный вид характеристики и ее линейность в достаточно широкой области напряжений свидетельствуют об омическом характере контактов. Поэтому в дальнейшем для определения удельного сопротивления пленок $\rho$ использовалась только правая ветвь вольт-амперной характеристики. Вид характеристик при различном содержании метана в водород-метановой смеси представлен на рис. $6, b$. 

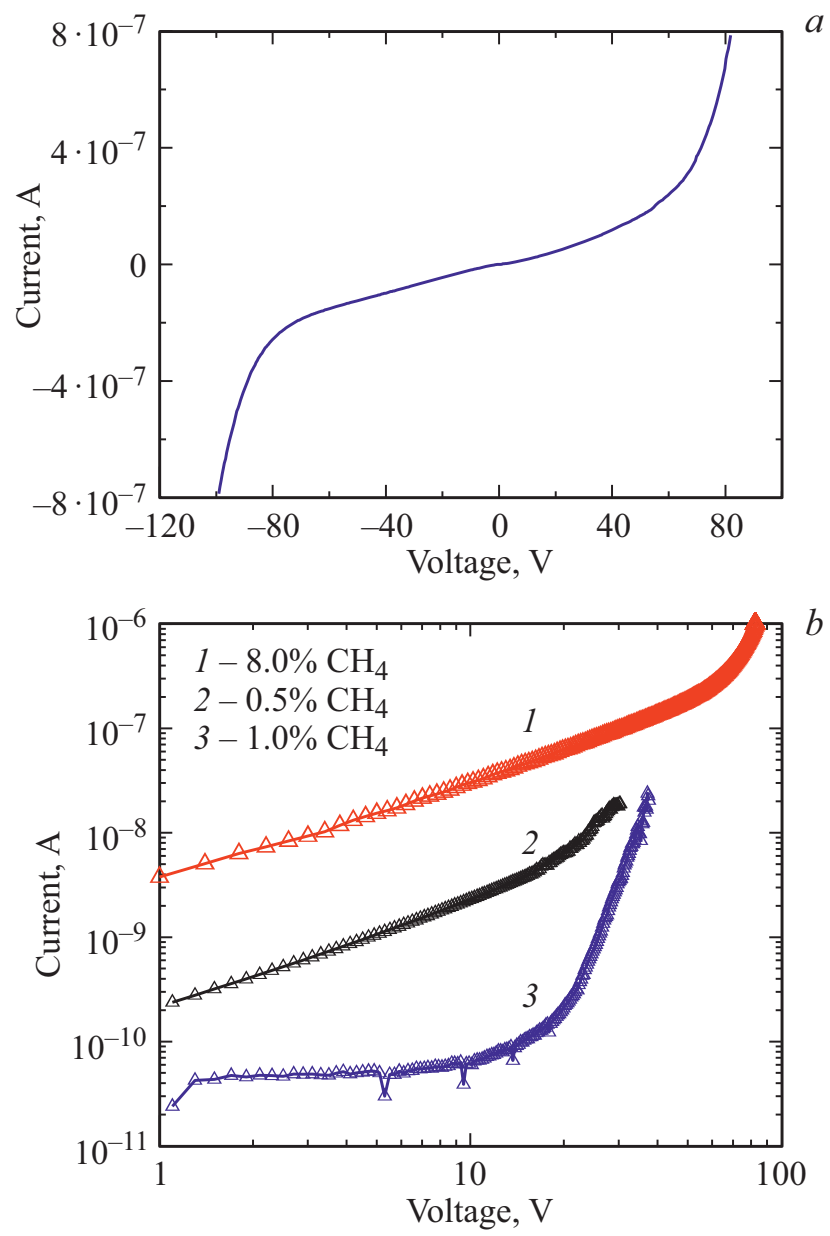

Рис. 6. Типичная вольт-амперная характеристика $(a)$ и вид характеристик в зависимости от процентного содержания метана $(b)$ для НКА пленок, выращенных в $\mathrm{H}_{2} / \mathrm{CH}_{4}$ газовой смеси.

Согласно работе [24], зависимость плотности $J$ тока от приложенного напряжения $V$ может быть описана следующей формулой:

$$
I=\frac{1}{\rho} \frac{V}{d}+\frac{9}{8} \varepsilon \theta \mu \frac{V^{2}}{d^{3}} .
$$

Здесь $\rho$ - удельное сопротивление, $\varepsilon-$ диэлектрическая проницаемость алмаза, $\mu$ - подвижность преобладающих носителей заряда, $\theta-$ отношение свободных зарядов к захваченным. При этом первый член уравнения описывает омическую часть вольт-амперной характеристики и связан с механизмом прыжковой проводимости [25] в области неалмазных границ между кристаллитами, а второй - связан с механизмом ограничения тока в режиме пространственного заряда и эмиссией электронов с глубоких уровней, образуемых дефектами в запрещенной зоне [26]. При этом наблюдаемый при пороговом напряжении $V_{p}$ излом на вольт-амперных характеристиках как раз и связан со сменой механизма проводимости. Отметим, что наличие омического участка вольт-амперной характеристики в области относи- тельно низких напряжений позволяет оценить значение удельного сопротивления для исследуемых НКА пленок. Результаты вычислений удельного сопротивления для выращенных пленок (без какой-либо последующей их обработки) представлены в таблице.

\section{3. Влияние высокотемпературного отжига на проводимость НКА пленок}

В настоящее время хорошо известно, что проводимость НКА пленок может быть существенно снижена с помощью высокотемпературной обработки в атмосфере азота [27], воздуха [28], кислородосодержащей атмосфере [29] или отжига в вакууме [30]. Целью такой обработки обычно является удаление неалмазной фазы или водорода, встраиваемого в алмазную пленку в процессе роста (гидрогенизации), из границ кристаллитов. В наших экспериментах выращенные пленки также были подвергнуты высокотемпературному отжигу. Обработка пленок, выращенных в различных газовых смесях, осуществлялась в вакууме $\left(10^{-5}\right.$ Торр) при температуре
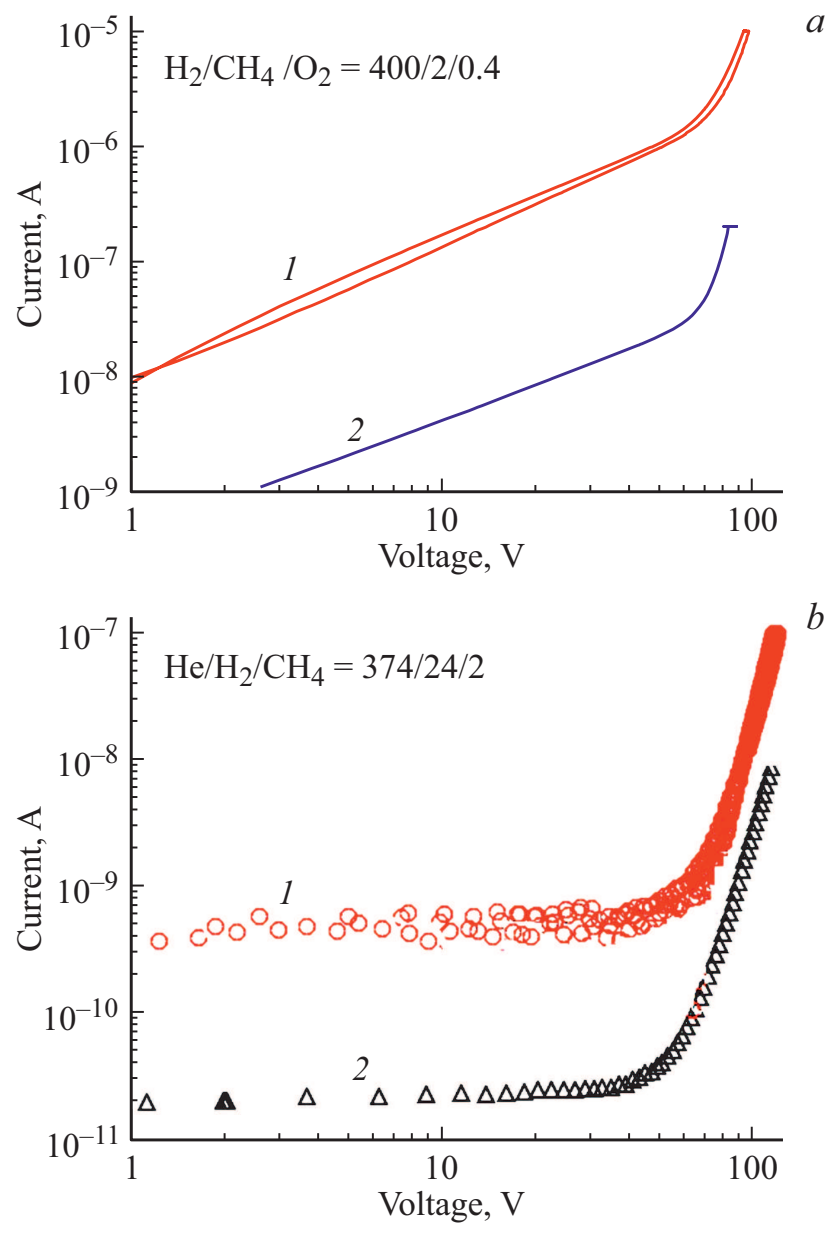

Рис. 7. Вольт-амперные характеристики НКА пленок, осажденных в смесях $\mathrm{H}_{2} / \mathrm{CH}_{4} / \mathrm{O}_{2}=400 / 2 / 0.4 \quad$ и $\mathrm{He} / \mathrm{H}_{2} / \mathrm{CH}_{4}=374 / 24 / 2$ до (кривые 1) и после (кривые 2) отжига в вакууме в течение 60 мин $\left(600^{\circ} \mathrm{C}, 10-5\right.$ Topp $)$. 
$600^{\circ} \mathrm{C}$ в течение одного часа. При этом исследования показали, что ни морфология пленок, ни их рамановские спектры не претерпевали существенных изменений. В то же время проводимость всех обрабатываемых пленок (независимо от режима осаждения) значительно уменьшалась. На рис. 7 приведены типичные изменения вольт-амперных характеристик НКА пленок толщиной 500 нм, осажденных в смесях $\mathrm{H}_{2} / \mathrm{CH}_{4} / \mathrm{O}_{2}=400 / 2 / 0.4$ и $\mathrm{He} / \mathrm{H}_{2} / \mathrm{CH}_{4}=374 / 24 / 2$, до и после отжига в вакууме.

Исследования показали, что, так же, как и в работе [30], отжиг в вакууме приводил к увеличению сопротивления НКА пленок на 2-3 порядка. Возрастание сопротивления не сопровождалось изменениями в рамановском спектре. Поэтому можно сделать вывод о том, что в нашем случае основным механизмом изменения проводимости пленок являлось не травление $s p^{2}$-фазы в области границ кристаллитов, а удаление водорода из всего объема пленки. Таким образом, высокотемпературный отжиг в вакууме является эффективным способом уменьшения проводимости НКА пленок.

\section{4. Заключение}

Нелегированные НКА пленки толщиной менее одного микрометра, выращенные на кремниевых подложках в трех исследуемых нами газовых смесях, имели микрокристаллическую структуру с размерами кристаллитов от 10 до 300 нм и различное количество неалмазного углерода $\left(s p^{2}\right.$-фазы) в межкристаллическом объеме в зависимости от условий синтеза. Такие нанокристаллические пленки по своей природе являются дефектным алмазом, электрическая проводимость которого определяется количеством дефектов и ионизируемых сайтов в материале, а также неалмазного углерода на границах кристаллитов. Кроме того, водород, остающийся внутри пленки после роста алмаза, также играет важную роль в проводимости, увеличивая проводимость получаемой пленки. Поэтому для получения НКА пленок в виде эффективных диэлектриков необходим высокотемпературный отжиг пленок, например, в вакууме.

Обработка пленок, выращенных нами в различных газовых смесях, в вакууме $\left(10^{-5}\right.$ Topp $)$ при температуре $600^{\circ} \mathrm{C}$ в течение одного часа показала, что ни морфология пленок, ни их рамановские спектры не претерпевали существенных изменений, в то же время проводимость всех обрабатываемых пленок (независимо от режима осаждения) значительно уменьшалась. Поэтому можно сделать вывод о том, что в нашем случае основным механизмом изменения проводимости пленок являлось не травление $s p^{2}$-фазы в области границ кристаллитов, а удаление водорода из всего объема пленки. Это, повидимому, связано с тем, что в выращиваемых пленках доля алмазной фазы существенно преобладала над фазой неалмазного углерода.

\section{Финансирование работы}

Работа выполнена в рамках государственного задания Федерального исследовательского центра Институт прикладной физики Российской академии наук, проект № 0035-2019-0003.

\section{Конфликт интересов}

Авторы заявляют, что у них нет конфликта интересов.

\section{Список литературы}

[1] O.A. Williams, M. Nesládek, J.J. Mareš, P. Hubík. In: Physics and Applications of CVD Diamond, ed. by S. Koizumi, C. Nebel, M. Nesladek (Wiley-VCH, 2008) p. 13.

[2] J.E. Butler, A.V. Sumant. Chem. Vap. Deposition, 14, 145 (2008).

[3] O.A. Williams. Diamond Relat. Mater., 20, 621 (2011).

[4] J. Kusterer, E. Kohn. In: CVD Diamond for Electronic Devices and Sensors, ed. by R.S. Sussmann (Wiley, UK, 2009) p. 469.

[5] A.V. Sumant, O. Auciello, R.W. Carpick, S. Srinivasan, J.E. Butler. MRS Bulletin, 35, 281 (2010).

[6] D.M. Gruen. Ann. Rev. Mater. Sci., 29, 211 (1999).

[7] V. Ralchenko, S. Pimenov, V. Konov, A. Khomich, A. Saveliev, A. Popovich, I. Vlasov, E. Zavedeev, A. Bozhko, E. Loubnin, R. Khmelnitskii. Diamond Relat. Mater., 16, 2067 (2007).

[8] K.J. Sankaran, Ken Haenen. In: Novel Aspects of Diamond, ed. by N. Yang (Springer, 2019) p. 123.

[9] I-Nan Lin, S. Koizumi, J. Yater, F. Koeck. MRS Bulletin, 39, 533 (2014).

[10] A.V. Sumant, P.U.P.A. Gilbert, D.S. Grierson, A.R. Konicek, M. Abrecht, J.E. Butler, T. Feygelson, S.S. Rotter, R.W. Carpick. Diamond Relat. Mater., 16, 718 (2007).

[11] Z.H. Shen, P. Hess, J.P. Huang, Y.C. Lin, K.H. Chen, L.C. Chen, S.T. Lin. J. Appl. Phys., 99, 124302 (2006).

[12] O.J.L. Fox, J. Ma, P.W. May, M.N.R. Ashfold, Yu.A. Mankelevich. Diamond Relat. Mater., 18, 750 (2009).

[13] M. Lions, S. Saada, M.A. Pinault, F. Andrieu, O. Faynot, P. Bergonzo. AIP Conf. Proc., 1292, 129 (2010).

[14] M. Lions, S. Saada, B. Bazin, M.-A. Pinault, F. Jomard, F. Andrieu, O. Faynot, P. Bergonzo. Diamond Relat. Mater., 19, 413 (2010).

[15] A. Aleksov, J.M. Gobien, X. Li, J.T. Prater, Z. Sitar. Diamond Relat. Mater., 15, 248 (2006).

[16] A.L. Vikharev, A.M. Gorbachev, M.A. Lobaev, D.B. Radishev. Diamond Relat. Mater., 83, 8 (2018).

[17] S.A. Bogdanov, A.M. Gorbachev, A.L. Vikharev, D.B. Radishev, M.A. Lobaev. Diamond Relat. Mater., 97, 107407 (2019).

[18] Детонационные наноалмазы. Технология, структура, свойства и применения, под ред. А.Я. Вуль, О.А. Шендерова (СПб., ФТИ им. А.Ф. Иоффе, 2016). ISBN: 978-593634-025-2

[19] А.Я. Вуль, В.Г. Голубев, С.А. Грудинкин, А. Kruger, Н. Naramoto. Письма ЖТФ, 28 (18), 77 (2002).

[20] A.E. Aleksenskiy, E.D. Eydelman, A.Y. Vul. Nanosci. Nanotechnol. Lett., 3 (1), 68 (2011). 
[21] A.T. Dideikin, A.E. Aleksenskii, M.V. Baidakova, P.N. Brunkov, M. Brzhezinskaya, V.Yu. Davydov, V.S. Levitskii, S.V. Kidalov, Yu.A. Kukushkina, D.A. Kirilenko, V.V. Shnitov, A.V. Shvidchenko, B.V. Senkovskiy, M.S. Shestakov, A.Ya. Vul. Carbon, 122, 737 (2017).

[22] R. Swanepoel. J. Phys. E: Sci. Instrum., 16, 1214 (1983).

[23] J. Robertson. Mater. Sci. Engin. R, 37, 129 (2002).

[24] G. Sharma, S. Sangodkar, M. Roy. Synth. Metals, 75, 201 (1995).

[25] P. Gonon, A. Deneuville, F. Fontaine, E. Gheeraert. J. Appl. Phys., 78, 6633 (1995).

[26] M.A. Lampert, P. Mark. Current Injection in Solids (Academic, N. Y., 1970).

[27] Y. Muto, T. Sugino, J. Shirafuji. Appl. Phys. Lett., 59, 843 (1991).

[28] P. Gonon, Y. Boiko, S. Prawer, D. Jamieson. J. Appl. Phys., 79, 3778 (1996).

[29] J.V. Manca, M. Nesladek, M. Neelen, C. Quaeyhaegens, L. De Schepper, W. De Ceuninck. Microelectron. Reliab., 39, 269 (1999).

[30] A.K. Kulkarni, K. Tey, H. Rodrigo. Thin Sol. Films, 270, 189 (1995).

Редактор А.Н. Смирнов

\section{Study of undoped nanocrystalline diamond films grown by microwave plasma-assisted chemical vapor deposition}

A.L. Vikharev' ${ }^{1}$, S.A. Bogdanov' ${ }^{1}$, N.M. Ovechkin ${ }^{1}$, O.A. Ivanov ${ }^{1}$, D.B. Radishev ${ }^{1}$, A.M. Gorbachev ${ }^{1}$, M.A. Lobaev' ${ }^{1}$, A.Ya. Vul' ${ }^{2}$, A.T. Dideikin ${ }^{2}$, S.A. Kraev ${ }^{1}$, S.A. Korolev ${ }^{1}$

${ }^{1}$ Federal research center Institute of Applied Physics of the Russian Academy of Sciences, 603950 Nizhny Novgorod, Russia

2 loffe Institute, 194021 St. Petersburg, Russia

Abstract Undoped nanocrystalline diamond films less than $1 \mu \mathrm{m}$ thick grown on $\mathrm{Si}$ (100) silicon by microwave plasma-assisted chemical vapor deposition at a frequency of $2.45 \mathrm{GHz}$ are studied. To obtain diamond dielectric films with maximum resistivity the deposition of films in three gas mixtures is investigated: hydrogenmethane mixture, hydrogen-methane mixture with the addition of oxygen and hydrogen-methane mixture with the addition of an inert gas. A relationship has been established between the growth conditions, structural and electrical properties of nanocrystalline diamond films. It is shown that for the use of nanocrystalline diamond films as effective dielectrics preliminary high-temperature annealing of the films is required, for example, in vacuum at a temperature of $600^{\circ} \mathrm{C}$ for one hour. 